\title{
AUTOMATIC WIPER USING PIEZOELECTRIC MATERIAL
}

\author{
Pallavi Saha \\ ${ }^{l}$ Student, Mechanical Engineering, College Of Engineering And Technology, Odisha, India
}

\begin{abstract}
'Piezoelectric Material' is a boon to the modern world where scarcity of resources is major problem. The project is all about running the wiper of a vehicle by using piezoelectric effect. In this process, a circuit is build using components like piezoelectric material, capacitor, relay and wiper motor. The circuit runs automatically when the rain drops presses the piezoelectric material which generates electricity, which in turn is stored in capacitor till a required voltage, is reached to close the relay system to run the wiper motor. This process helps us to utilize the kinetic energy of the rain drops which would otherwise have gone wasted in the form of heat energy, sound energy and vibratory energy.
\end{abstract}

Key Words: Piezoelectric Effect, Transducer, Sensor, Wiper.

\section{INTRODUCTION}

"Conservation of energy" is an important issue hovering all around the world today. All over the world, scientists are trying to find out ways of using more of renewable resources in all the fields instead of non-renewable resources which are in verge of extinction. In everyday life, large amount of energy are getting wasted in different equipment. One of them is the energy produced when the rain drops strikes the glass of a car. The rain drops when strikes the glass, the kinetic energy of rain drops are converted into vibratory and sound energy which goes unused. In this project, an effort is put to use this energy from rain drops to generate electricity to run the wiper of a car. Here piezoelectric material is used to convert the pressure of rain drops into electric energy.

\section{OBJECTIVES OF THE PROJECT}

$>$ To conserve energy from rain drops which gets wasted

$>\quad$ Use to run the wiper of a car

$>$ Supplies power at the correct time

$>$ Useful in energy harvesting

$>$ Prevents unnecessary working of wiper when very light particles (dusts) hits the glass

\section{HARDWARE COMPONENTS REQUIRED}

\subsection{Piezoelectric Sensors}

These type of sensors are used to measure the changes in pressure, force, temperature, strain or acceleration by converting these values to an electrical charge. Here PVDF (polyvinylidene fluoride) polymer is used to convert mechanical energy into electrical energy. The polymer starts vibrating when a rain drop hit the PVDF membrane. The electrodes that are placed on the PVDF are used to recover the electrical charges generated by these vibrations.

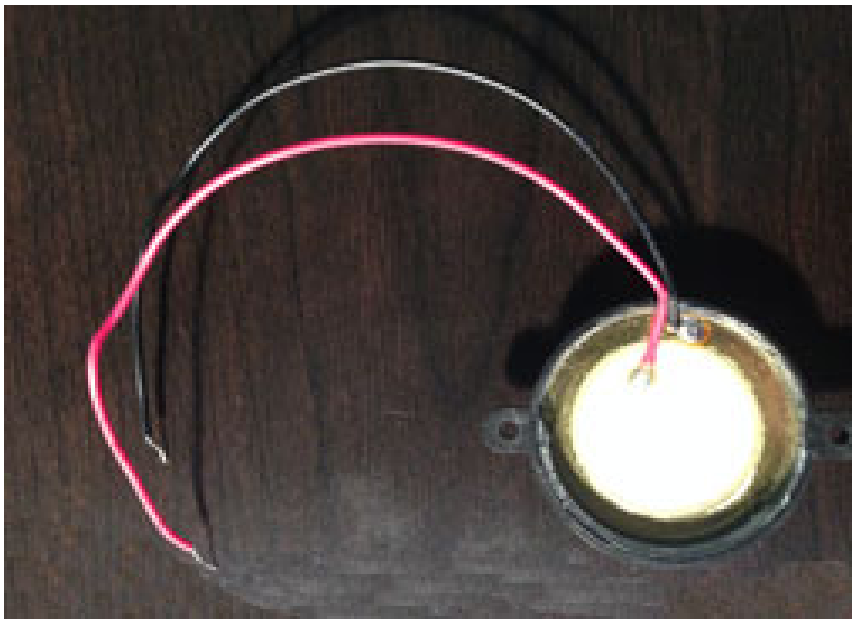

\subsection{Piezoelectric Transducer}

The principle on which piezoelectric transducer works is piezoelectric effect. When we apply mechanical stresses to some materials along certain planes (transverse, longitudinal, shear etc ), electric voltage is produced. The output voltage obtained from these materials is proportional to the applied stress or force due to piezoelectric effect. The output voltage can be calibrated against the applied stress or force so that the measured value of the output voltage will directly give us the value of the applied stress or force.

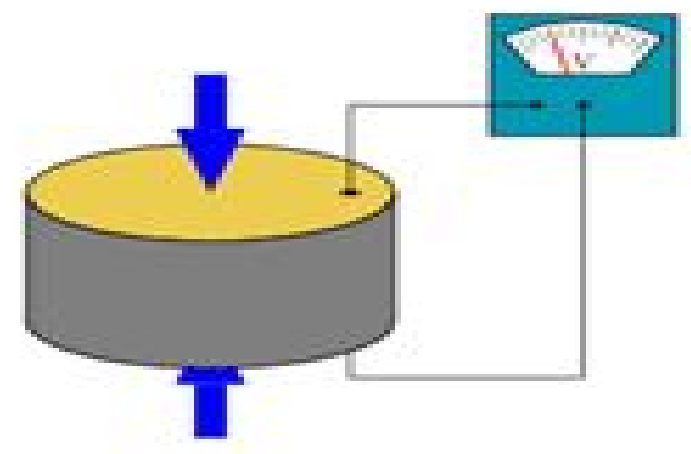




\section{$\underline{\text { 3.3 Capacitor }}$}

Capacitors are simple energy storing passive device which stores energy in the form of electrical charge producing a potential difference across its plates. In this project, it gets charged by the energy coming from piezoelectric materials and gets discharged when required power is obtained to run a wiper of car.

\subsection{Relay}

Relay is defined as an electromechanical device through which we can switch a heavy load ON or OFF with a perfect amount input of current \& voltage. In this project, we use relay to maintain the current flowing into the wiper motor. The relay connects the circuit when a required voltage (say $12 \mathrm{~V}$ ) is reached in a capacitor which activates the wiper. It prevents the unnecessary functioning of wiper when dust particles hit the piezoelectric material as the pressure applied by them is too low to connect the relay.

\subsection{Wiper Motor}

The main objective of the wiper motor is to run the wiper of a car. The voltage requirement for such type of motor is 12 volts DC. The safe limit at which the motor can run is 13.5 volts. A voltage higher than that is not advisable. The current requirement is 1.6 amps at $70 \mathrm{rpm}$ and 0.9 amps at $41 \mathrm{rpm}$. These are the current ratings when the motor is spinning at no load.

\section{FUNCTIONAL VIEW OF CONTROLLING}

\section{SYSTEM.}

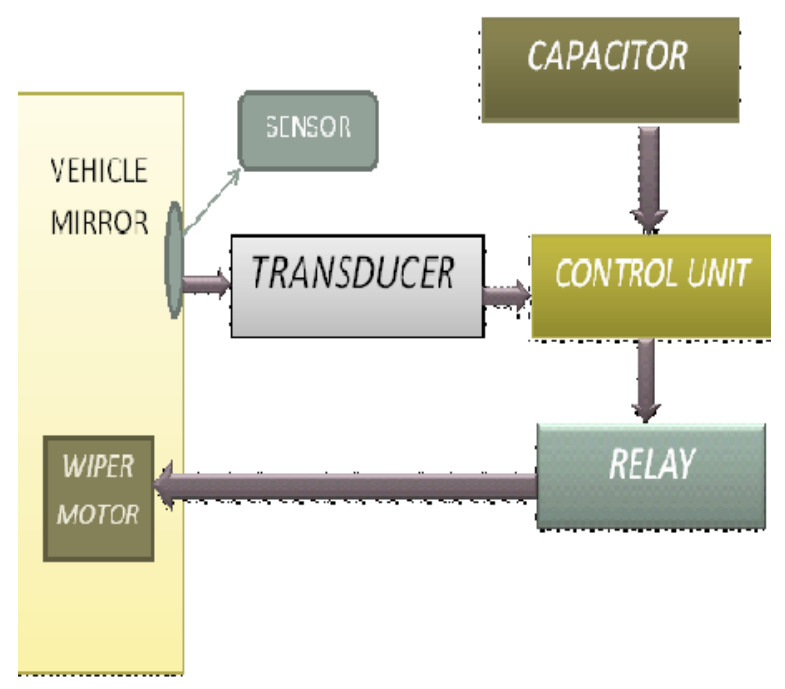

\section{WORKING}

As shown in the diagram, a piezoelectric sensor is used to sense the pressure of the rain drops and convert them into a measurable quantity. In this paper, we will be using polyvinylidene fluoride polymer. When the raindrops hit the 25-micrometer-thick PVDF on the vehicle's front mirror, the PVDF polymer starts vibrating. The electrodes that are present in the PVDF are used to recover the electrical charges generated by the vibrations. After conducting experiment with rain drops of different sizes, different falling heights and different speeds, it was found that slow falling raindrops generate the most energy. For low drop heights, larger electric energy is obtained. For largest size of raindrops largest vibrations are caused on the PVDF which generates largest amount of electric energy. Thus it was concluded that the energy developed depends directly on the size of the piezoelectric membrane, the size of the rain drops and their frequency. The available energy per drop varies between 2 micro joule to 1 milli-joule depending on its size.

In piezoelectric sensor, a piezoelectric material can be cut in many ways and it produces three operational modes:

\section{- TRANSVERSE EFFECT \\ - LONGITUDINAL EFFECT \\ - $\quad$ SHEAR EFFECT}

Among these three modes, transverse mode would make it possible to tune sensitivity very finely on the applied force and element dimension. So transverse mode is preferred.

To ensure that an applied pressure specifically loads the elements in one direction, a thin membrane and a large base is used. When this is exposed to vibrations, the pressure sensors would show false signal. So in order to avoid it, acceleration compensation elements are used in addition to the pressure sensing elements.

The piezoelectric transducer that has been used has very high DC output impedance and this can be modeled as a proportional voltage source and filter network. The source voltage $(\mathrm{V})$ is directly proportional to the applied force, pressure and strain. Now the output signal can be related to the mechanical force.

The electrical energy that is generated in the transducer is stored in a capacitor therefore charging it. The capacitor can be discharged when we require energy. It is also termed as short-term battery or secondary battery.

As we can see in the diagram, an automatic relay is connected to regulate the current flowing through to the wiper motor. The wiper motor requires $12 \mathrm{~V}$ to operate and the safe limit is $13.5 \mathrm{~V}$. So the relay starts the motor only when the required voltage is reached. It prevents the unnecessary running of wiper when dust particles pressurise the piezoelectric membrane on the front glass as very little amount of energy is generated by dust particles.

\section{ADVANTAGES}

Kinetic energy of falling raindrops is conserved

$>$ Prevents the wiper from running in case of dust particles

$>$ Supplies power in the correct time, which avoids any wastage of energy

$>\quad$ It is an energy harvesting technique which eliminates the need of other power sources (external battery, fuels etc.) 


\section{CONCLUSIONS}

Hence, a process of conservation of energy is explained in this project where the energy from falling raindrops is converted into useful electrical energy. Thus it prevents the wastage of that energy in the form of vibratory, heat energy or sound energy. The piezoelectric elements make it possible to convert the energy into useful electrical energy which in turn is used to run a wiper of a vehicle.

\section{REFERENCES}

[1]. Alberts, T., Liu, S., And Lally, R., "Investigation Of An Inexpensive Piezoelectric Pressure Sensor For Internal Combustion Engine Spark Timing Control," SAE Technical Paper 2006-01-0183, 2006, Doi:10.4271/2006-01-0183.

[2]. Higuma, A., Suzuki, T., Yoshida, M., Oguri, Y. Et Al., "Improvement Of Error In Piezoelectric Pressure Transducer," SAE Technical Paper 1999-01-0207, 1999, Doi:10.4271/1999-01-0207.

[3]. J. Vib. Acoust 123(4), 533-535 (May 01, 2001) (3 Pages)Doi:10.1115/1.1389459

[4]. Fundamentals Of Vehicle Dynamics, A Book By Thomas D. Gillespie

\section{BIOGRAPHIES}

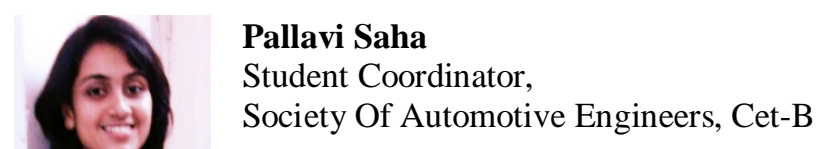

